\title{
Fluoride Therapy Comprehensive Plan in Primary Schools in Iran
}

\author{
Karimi MD* \\ Pediatric Dentistry Department, Sepideh Dental Clinic, Iran

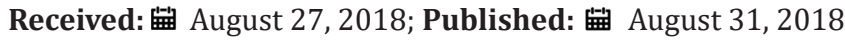 \\ *Corresponding author: Karimi MD, Pediatric Dentistry Department, Sepideh Dental Clinic, Iran
}

\section{Short Communication}

When I was spending my childhood in southern Iran, I encountered people whose teeth were brownish-yellow with white spots. I always wondered why their teeth are looking ugly. Are they not doing oral hygiene? But when I got into the dental school, I realized that this was due to excessive fluoride in drinking water. Interestingly, the percentage of dental caries in these individuals was much lower than others. From four years ago, following the popularity of Varnish Fluoride in the international dental community, the Ministry of Health in Iran has implemented the plan for children's fluoride therapy in primary schools in the country. In the past few years, the project has been welcomed by parents and the dental community. Students in elementary schools were examined every six months by dentists and treated by varnish fluoride for free. Every year based on this project, from the start of the school year, trained health personnel will be active in the villages and in the cities so that school health educators and oral hygiene practitioners will cover all the elementary schools across the country for varnish fluoride therapy.

In the treatment debate, the focus is that schools and health centers throughout the country will use fixed and mobile dental units that will provide health care based on the student's health electronic card. The problems of teeth caries in adults are gradually formed from the time of childhood, but according to the authorities, the rate of dentistry visitation is very low in childhood. According to statistics, about 25 percent of children before entering school are never visited by a dentist, while 80 percent of the caries of primary teeth occur due to deep grooves on the surfaces of the teeth [1]. Also, the statistics indicate that the rate of dental caries among Iranian children is three times the global standards, so that children and adolescents aged 10-12 years old have on average 4 decayed or extracted teeth [2]. Dr. Samadzadeh, Head of the Oral Health Department of the Ministry of Health said to the news" According to studies, Varnish Fluoride Therapy reduces tooth decay by about 40 to 60 percent. The recent study shows the latest DMFT index for children up to 12 years of age is 2.9 . About 82 percent of this index is related to tooth decay.
In other words, every 12-year-old has on average 4 damaged teeth, drawn or restored. We are hoping that with the implementation of this national and targeted program, we can reduce this index to one by one over the next six years; of course, reaching it is very difficult to achieve [3]." Another of these goals is the stress reduction in children. Most children are afraid of visiting a dental office, and sometimes they have bitter memories of dental experiences, therefore, the painlessness of doing Varnish fluoride can reduce the fear of children and give them happy memories of dentistry. In other studies, in Sepideh Dental Clinic and Apple Dental Clinic, we conducted a brief study on the referred pediatric patients. After two courses of fluoride therapy, and keeping good oral hygiene by children, a significant reduction in the number of dental caries was observed in this group of children [4,5].

One remarkable point is that this decrease was more evident in the children who were from a wealthy family in the community and whose parents had a university education [5]. However, in recent years, the oral health improvement plan has been somewhat successful, but performing only dental preventive methods without children's education and parenting advice will not be a long-term sustainable plan. It is imperative for everyone to use fluoridecontaining toothpaste at home. Since the risk of caries in the adult teeth is far more than that of children and adolescents, as a result, these people may require more fluoride treatments such as Varnish Fluoride.

\section{References}

1. Samadzadeh H (2014) Influence of fluoride on reducing tooth decay. Ministry of Health, Country Guide.

2. Karimi M (2018) Each Iranian teenager has four damaged teeth. EC Dental science 17(8).

3. http://dandane.org/

4. (2017) Archives of survey of Apple dental clinic records.

5. (2017-2018) A survey of Sepideh dental clinic. 
ISSN: 2574-1241

DOI: 10.26717/BJSTR.2018.08.001672

Karimi MD. Biomed J Sci \& Tech Res

(c) (P) This work is licensed under Creative

Submission Link: https://biomedres.us/submit-manuscript.php

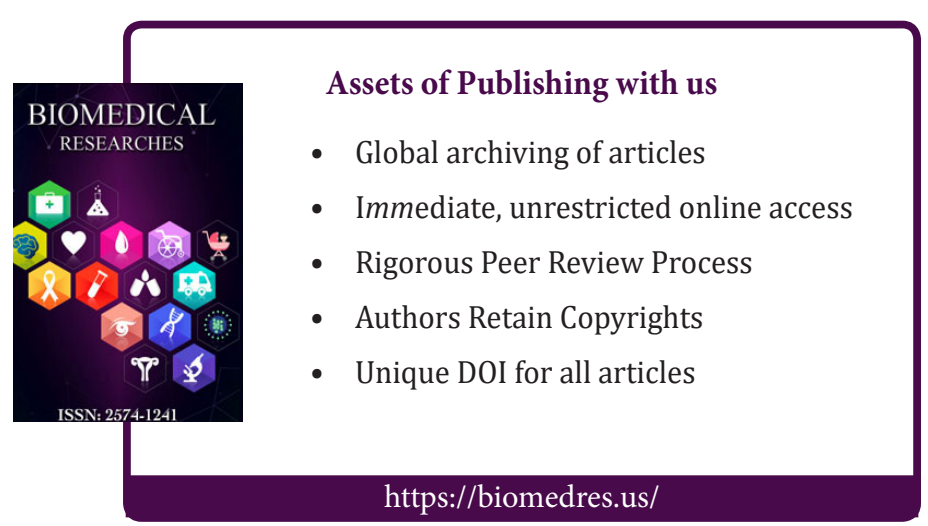

